\title{
PENGEMBANGAN ALAT UKUR INTENTION TO LEAVE SCALE BAGI PERWIRA TNI AD
}

\author{
Ferdi Hilman*, Megawati Batubara, dan Zahrotur R. Hinduan \\ Fakultas Psikologi, Universitas Padjadjaran, \\ Jl. Raya Bandung Sumedang KM 21, Jatinangor, Sumedang, Jawa Barat, Indonesia 45363 \\ Email: hilman.psiad@gmail.com
}

\begin{abstract}
ABSTRAK
Permasalahan retensi merupakan permasalahan yang harus dihadapi banyak angkatan bersenjata di seluruh dunia. Di sisi lain, permasalahan ini juga merupakan tantangan bagi TNI AD. Angka retensi pada TNI AD relatif stabil, yaitu dengan jumlah kurang dari $1 \%$ per tahunnya. Meskipun begitu, TNI AD harus mampu memastikan bahwa para perwira yang memutuskan untuk pensiun dini bukanlah perwira potensial, seperti telah mengikuti pendidikan staf dan komando atau pernah menduduki jabatan sebagai komandan yang berprestasi, karena investasi yang telah dilakukan akan menjadi sia-sia. Tujuan dari penelitian ini adalah untuk mengembangkan adaptasi alat ukur Intention to Leave (ITL) untuk TNI AD. Instrumen yang dikembangkan didasari oleh teori dari Meyer et al. (1993) yang mendefinisikan tiga dimensi yang berhubungan dengan intention to leave, yaitu how frequently thinks about leaving, how likely search for a job in another organization, dan how likely individual will actually leave within next year. Skala ITL dalam penelitian ini disajikan kepada 73 perwira menengah yang berdinas di Sekolah Staf dan Komando TNI AD dengan menggunakan online platforms. Hasil menunjukkan bahwa construct reliability pada tiap dimensi adalah sebesar $0,834,0,841$ dan 0,859 secara berurutan. Hal ini mengindikasikan bahwa reliabilitas pengukuran berada pada rentang yang dapat diterima. Melalui perhitungan second-order confirmatory factor analysis, diperoleh hasil $\chi^{2}=1.922, \mathrm{P}=$ 0,004, RMSEA $=0,113$, SRMR $=0,050$, dan CFI $=0,97$. Hasil tersebut berada dalam kategori model yang marginal dan good fit, sehingga secara internal mendukung validitas instrumen dalam mengukur ITL. Saran bagi penelitian selanjutnya yaitu perlu mempertimbangkan sampel yang lebih besar, karakter demografi, latar belakang budaya, dan dapat diberikan pada Golongan Bintara atau Golongan Tamtama.
\end{abstract}

Kata kunci: intention to leave; pensiun dini; TNI AD

\section{Development of Intention to Leave for Indonesian Army Officer Scale}

\begin{abstract}
The problem of retention is something that many armed forces have to deal with. In a different way, this issue is also a challenge for the Indonesian Army. While the number of retentions in the Indonesian Army is relatively stable at less than $1 \%$ per year, however, the Indonesian army must be able to make sure that the officers who leave are not the potential ones, those who have attended staff and command school education, or have even served as good commanders, because the investment that the army has given would be in vain. The purpose of this study is to develop the Intention to Leave (ITL) scale adapted for the Indonesian Army. The instrument was developed based on the Meyer et al., (1993) definition of three dimensions related to intention to leave, namely how frequently thinks about leaving, how likely search for a job in another organization, and how likely individual will actually leave within next year. The ITL scale was delivered using online platforms to 73 Indonesian Army officers who had served in Indonesian Army Staff and Command School. With 100\% return rate, the results showed that the construct reliability for each of the dimensions was $0.834,0.841$, and 0.859 consecutively, indicating the reliability of the measure was within an acceptable range. Second-order confirmatory factor analysis resulted in $\chi^{2}=1.922 ; \mathrm{p}=0.004$; RMSEA $=$ .113 ; SRMR $=0.050$ and CFI $=0.97$, suggesting a marginal and good fit of the model, thus internally supporting the validity of the instrument in measuring ITL. Suggestions for future research, include the inclusion of a larger sample size, other demographics and cultural backgrounds, as well as non-commissioned officers and enlisted in the model.
\end{abstract}

Keywords: intention to leave; voluntary turnover; Indonesian army. 


\section{PENDAHULUAN}

Kemampuan mempertahankan prajurit (retensi) merupakan permasalahan yang dihadapi oleh banyak angkatan bersenjata di dunia. Angkatan bersenjata Inggris dilaporkan telah kehilangan hampir 36.000 prajuritnya selama tahun 2017 sampai 2018 (United Kingdom Ministry of Defence, 2020). Kemudian, angkatan bersenjata Belgia juga menghadapi situasi yang cukup sulit dimana $30 \%$ prajurit yang telah direkrut mengundurkan diri pada bulan pertama saat dilaksanakan pendidikan dasar militer. Terdapat dua alasan yang membuat prajurit memutuskan untuk keluar, yaitu ketertarikan terhadap alternatif pekerjaan lain di luar militer dan ketidakpuasan dengan organisasi militer (Schreurs \& Lescreve, 2001). Permasalahan retensi ini juga merupakan tantangan bagi angkatan bersenjata Indonesia, khususnya TNI AD sebagai angkatan bersenjata terbesar dengan jumlah kurang lebih sekitar 300.000 personel. Sampai saat ini, jumlah prajurit yang pensiun dini di TNI AD tidak sebesar negara lain, yaitu dengan angka kurang dari $1 \%$ per tahun, di mana tercatat sebanyak 113 perwira mengundurkan diri pada tahun 2017, 102 di tahun 2018, dan 121 pada tahun 2019. Meski demikian, TNI AD harus mampu memastikan bahwa para perwira yang mengundurkan diri bukanlah perwira potensial, misalnya telah mengikuti sekolah Staf dan Komando atau pernah menduduki jabatan komandan. Permasalahan voluntary turnover, atau biasa disebut dengan pensiun dini, di dalam lingkungan militer membutuhkan perhatian dari seluruh organisasi angkatan bersenjata. Voluntary turnover yang disfungsional sangat merugikan organisasi, khususnya organisasi militer, karena mendidik rekrutan untuk menjadi prajurit, kemudian memberikan penugasan dalam masa dinas tertentu, serta memberikan promosi jabatan dan Pendidikan yang lebih tinggi membutuhkan biaya yang tidak sedikit (Sümer \& van de Ven, 2007).

Dalam penelitian Mafini \& Dubihlela (2013) yang terkait dengan military turnover dijelaskan bahwa mengetahui penyebab terjadinya turnover sangat diperlukan untuk memperoleh informasi terkait strategi retensi, serta mengetahui hal-hal apa saja yang membuat para prajurit meninggalkan organisasi atau profesinya. Berdasarkan Military Personnel: Perspectives of Surveyed Service Members in Retention Critical Specialties: Briefing Report to Congressional Requesters yang disusun oleh US General Accounting Office (GAO, 1999), kepuasan, kompensasi, kesempatan promosi, dan kualitas hidup merupakan prediktor penting terkait turnover (GAO, 2000). Selain itu, kepuasan yang diperoleh dari pengalaman selama menjalani masa dinas juga merupakan salah satu faktor yang melatarbelakangi retensi pada prajurit aktif (Kocher \& Thomas, 1994). Kompensasi yang diberikan oleh angkatan bersenjata telah terbukti memberikan dampak secara langsung terhadap retensi personel (Daula \& Moffitt, 1995). Personel militer membandingkan gaji dan pendapatan mereka dengan posisi yang sebanding di sektor sipil, serta mempertimbangkan ketersediaan alternatif lain. Ketika gaji militer lebih rendah daripada gaji di sektor sipil, tingkat retensi pun menurun. Personel militer dinilai identik dengan "menghindari risiko", sehingga angka pengangguran yang tinggi juga akan menyebabkan personel militer tetap berada di organisasinya. Jika tidak, saat tingkat pengangguran rendah, pemberian bonus juga dapat membantu meningkatkan retensi dengan meningkatkan kompensasi keseluruhan (Hosek \& Peterson, 1985).

Faktor lain yang tidak kalah penting dalam retensi militer adalah sikap pasangan, kurangnya pemahaman, dan harapan yang tidak terpenuhi selama penugasan meningkatkan turnover (Bowen, 1986). Selain itu, personel perwira umumnya berpendidikan tinggi, sehingga peluang mereka untuk bekerja secara nasional lebih terbuka dibandingkan dengan prajurit lain seperti kelompok Tamtama (Stone et al., 1998). Penelitian yang dilakukan Marcotte (2000) pun menunjukkan adanya konsistensi hubungan antara tingkat Pendidikan yang tinggi dengan kesempatan kerja. Berdasarkan hal tersebut, maka subjek dalam penelitian ini adalah para prajurit TNI AD dari golongan perwira.

Voluntary turnover adalah salah satu perilaku yang paling banyak dipelajari dalam penelitian manajemen (Griffeth, 2000). Terdapat banyak model multivariasi dan pengujian empiris dalam aliran penelitian ini yang telah meningkatkan pengetahuan tentang intention to leave. Model proses berfokus pada "bagaimana individu sampai pada keputusan akhir dan memutuskan untuk berhenti", sedangkan model konten berfokus pada "mengapa individu meninggalkan organisasi" (Maertz \& Campion, 2004).

Dampak intention to leave (ITL) terhadap efektivitas organisasi dan semangat kerja karyawan tetap menjadi fokus dalam beberapa studi para peneliti organisasi (Chen et al., 2011). Dengan mengidentifikasi determinan dari keinginan karyawan untuk berhenti, perilaku turnover pun dapat 
diprediksi secara lebih akurat sehingga langkah-langkah untuk mencegah pergantian dapat ditangani lebih awal (Van Schalkwyk et al., 2010).

Beberapa studi yang telah dilakukan, baik di sektor sipil maupun militer, telah mengidentifikasi bahwa ITL merupakan prediktor yang sangat signifikan dari voluntary turnover (Price \& Mobley, 1983). Di lingkungan militer, beberapa studi telah menemukan hubungan antara budaya dan iklim organisasi dalam retensi prajurit aktif $(\mathrm{GAO}, 2000)$. Berkaitan dengan hal tersebut, maka dapat dipahami bahwa terdapat beberapa hal yang melatarbelakangi munculnya keinginan prajurit untuk mengundurkan diri. Penelitian terkait retensi prajurit aktif di militer telah mengidentifikasi sejumlah indikator penting yang terkait dengan turnover. Sebagaimana yang diidentifikasi dalam voluntary turnover, ITL tetap menjadi faktor paling signifikan dalam memprediksi pergantian (GAO, 1999). Pentingnya ITL dalam memprediksi voluntary turnover merupakan salah satu alasan bagi peneliti untuk mengembangkan alat ukur ini, yaitu sebagai langkah antisipatif TNI AD agar tidak kehilangan perwira potensialnya. Selanjutnya, ITL didefinisikan sebagai "persepsi individu tentang kemungkinan menghentikan keanggotaan dalam suatu organisasi" (Mueller \& Price, 1990). ITL mengacu pada tingkat kemungkinan seorang karyawan akan menghentikan keanggotaannya dalam organisasi kerja (Spreitzer \& Mishra, 2002).

ITL dipandang sebagai variabel dependen dan digunakan sebagai indikasi kemungkinan seseorang akan meninggalkan organisasi dalam waktu dekat. Para pekerja yang memiliki intention to leave dapat dilihat dengan mengukur tiga dimensi (Meyer et al., 1993), yaitu how frequently thinks about leaving, how likely search for a job in another organization, dan how likely individual will actually leave within next year. Dengan konstrak yang sama, penelitian sebelumnya terkait pengukuran intention to leave yang dilakukan kepada 366 siswa keperawatan dan 603 perawat menunjukkan kriteria alat ukur dengan hasil validitas dan reliabilitas yang baik (Meyer et al., 1993). Selain itu, Stallworth (2003) juga melakukan pengukuran kepada 107 akuntan publik yang berada di bawah naungan American Institute of Certified Public Accountant dengan hasil validitas dan reliabilitas yang baik pula.

Sampai saat ini, terdapat beberapa alat ukur yang digunakan untuk mengukur ITL. Meski demikian, alat ukur ITL yang ada masih bersifat umum dan digunakan pada organisasi nonmiliter. Organisasi militer memiliki kekhasan dan situasi yang berbeda dengan organisasi lainnya. Hal tersebut mendasari pentingnya melakukan pengembangan alat ukur ITL yang valid dan reliabel khususnya di lingkungan organisasi TNI AD. Alat ukur ini diharapkan bermanfaat bagi TNI AD dalam memprediksi prajurit yang akan melakukan voluntary turnover, sehingga dapat dilakukan langkah-langkah antisipatif untuk mencegah perwira potensial TNI AD mengundurkan diri. Skala ini dikembangkan dengan mengukur konstrak yang dikembangkan oleh Meyer et al. (1993) yang selanjutnya diturunkan dalam bentuk item per item. Kemudian, dilakukan pengujian terhadap perwira TNI AD hingga diperoleh alat ukur yang baik agar dapat bermanfaat bagi organisasi pertahanan, khususnya TNI AD, serta organisasi pemerintahan dengan karakteristik yang sama. Hingga saat ini, pengembangan alat ukur ITL di lingkungan organisas TNI AD belum pernah ada. Berdasarkan penjelasan tersebut, maka dikembangkanlah adaptasi alat ukur ITL dalam penelitian ini agar dapat digunakan untuk memprediksi keinginan pensiun dini pada para perwira.

\section{METODE}

Pengumpulan data yang dilakukan dalam penelitian ini bertujuan untuk menguji skala ITL dan melakukan pemeriksaan sifat psikometri seperti uji validitas dan uji reliabilitas. Validitas dan reliabilitas konstrak dari indikator-indikator pembentuk konstrak laten diperoleh dengan melakukan CFA atau confirmatory factor analysis (Latan, 2012). Adapun penggunaan confirmatory factor analysis dalam pengujian validitas dan realibilitas terhadap instrumen ini dilakukan agar diperoleh data yang valid dan reliabel. Dengan kata lain, pengujian ini digunakan untuk melakukan pengukuran model (model measurement) dalam menggambarkan sebaik apa aspek-aspek dan indikator-indikator dapat digunakan untuk pengukuran ITL. Second-order confirmatory factor analysis merupakan model pengukuran yang terdiri dari dua tingkat. Tingkat pertama analisis dilakukan dari konstrak laten aspek ke indikator-indikatornya, dan analisis kedua dilakukan dari konstrak laten ke konstrak aspeknya (Latan, 2012). Menurut Hair et al. (2010), metode CFA tidak hanya dapat melakukan pengujian validitas konstrak (construct validity), tetapi juga reliabilitas konstrak (construct reliability). 
Proses pengembangan alat ukur ITL dilakukan melalui tahapan desain dan evaluasi (Kerlinger, 2006). Meskipun penelitian tentang ITL telah banyak dilakukan baik disektor sipil maupun militer, namun demikian pengembangan alat ukur ini belum pernah dilakukan, khususnya di lingkungan TNI. Intention to leave adalah tingkat keinginan seorang karyawan untuk berhenti dari pekerjaannya dalam jangka waktu tertentu (Mueller \& Price, 1990). Intention to leave akan muncul di benak seseorang ketika seorang karyawan merasa bahwa organisasi tempatnya bekerja tidak memenuhi keinginannya atau merasa tidak membutuhkannya lagi (Maertz \& Campion, 2004; Firth et al., 2004). Terdapat tiga indikator untuk mengetahui keinginan seseorang untuk keluar dari pekerjaannya, yaitu "seberapa sering berpikir untuk keluar", "seberapa besar kemungkinan mencari pekerjaan di organisasi lain", dan "seberapa besar kemungkinan individu akan benar-benar pergi dalam beberapa tahun ke depan (Meyer et al., 1993). Peneliti mengembangkan item-item dengan menurunkan konstrak dari ketiga indikator tersebut. Setelah membangun pernyataan item, selanjutnya peneliti melakukan uji setiap item dengan dua reviewer. Review dilakukan oleh reviewer dengan kualifikasi masing-masing, yaitu ahli psikometri dan perwira menengah TNI AD. Proses review dilakukan selama bulan Juni sampai dengan Juli 2020.

Selanjutnya, peneliti melakukan uji coba terhadap instrumen yang telah dikembangkan untuk mendapatkan informasi terkait daya beda dan nilai loading factor yang tepat untuk setiap item sehingga diharapkan diperoleh instrumen yang reliabel serta model yang sesuai. Jika daya beda $<0,3$, item tersebut akan dibuang. Item juga akan dibuang jika memiliki nilai loading factor $<0,5$. Setelah melakukan uji reliabilitas instrumen, peneliti melakukan uji validitas alat ukur dengan mengukur validitas konstrak (construct validity), yaitu dengan cara mengukur sejauh mana komponen internal alat ukur sesuai dengan konstrak yang diukur. Teknik uji validitas alat ukur dilakukan menggunakan second-order confirmatory factor analysis melalui program LISREL 8.80 Full Version dengan path analysis. Path analysis adalah analisis statistik yang menggunakan sistem persamaan untuk melihat hubungan sebab akibat di antara dua atau lebih variabel. Menurut Hu \& Bentler (1999) validitas hubungan terhadap dependent variable melalui analisis CFA dapat diketahui dengan melihat kesesuaian hasil analisis terhadap kriteria fit. Path diagram menunjukkan nilai signifikansi ( $t$-value) dan nilai loading factor yang menunjukkan hubungan antara variabel laten dan indikator pengukuran. Pada penelitian ini, variabel laten adalah intention to leave dengan faktor dan item dari tiap faktornya. Apabila nilai $t$-value dan loading factor sesuai dengan kriteria yang digambarkan pada bagian method, maka alat ukur dinilai memiliki validitas yang cukup baik untuk menjelaskan variabel laten.

Penelitian ini dilakukan di Sekolah Staf dan Komando TNI Angkatan Darat dengan jumlah personel perwira 119 orang dengan komposisi sebagai berikut:

Tabel 1. Data Perwira Menengah Berdasarkan Pangkat

\begin{tabular}{lc}
\hline \multicolumn{1}{c}{ Pangkat } & Jumlah \\
\hline Kolonel & 88 \\
Letnan kolonel & 18 \\
Mayor & 13 \\
Total & 119 \\
\hline
\end{tabular}

Dengan menggunakan tiga strata dan batas kesalahan 0,1 , maka jumlah peserta paling sedikit adalah 55 subjek dengan komposisi yang tercantum pada tabel berikut:

Tabel 2. Jumlah Responden

\begin{tabular}{lc}
\multicolumn{1}{c}{ Pangkat } & Jumlah \\
\hline Kolonel & 40 \\
Letnan kolonel & 9 \\
Mayor & 6 \\
Total & 55 \\
\hline
\end{tabular}

Penelitian ini selanjutnya melibatkan 73 orang perwira yang bertugas di Sekolah Staf dan Komando TNI Angkatan Darat. Peneliti menggunakan stratified random sampling sebagai teknik pengumpulan sampel penelitian, dengan mempertimbangkan ketersediaan responden di Sekolah Staf dan Komando TNI Angkatan Darat. Adapun data demografi responden dapat dilihat pada Tabel 3.

Tabel 3. Data Demografi Responden 


\begin{tabular}{|c|c|}
\hline Kategori & $f$ \\
\hline \multicolumn{2}{|l|}{ Jenis kelamin } \\
\hline Laki-laki & 69 \\
\hline Perempuan & 4 \\
\hline \multicolumn{2}{|l|}{ Status } \\
\hline Menikah & 73 \\
\hline Tidak menikah & 0 \\
\hline \multicolumn{2}{|l|}{ Status Pasangan } \\
\hline Bekerja & 26 \\
\hline Tidak bekerja & 47 \\
\hline \multicolumn{2}{|l|}{ Pangkat } \\
\hline Kolonel & 48 \\
\hline Letnan kolonel & 13 \\
\hline Mayor & 12 \\
\hline \multicolumn{2}{|l|}{ Korps } \\
\hline Infanteri & 44 \\
\hline Kavaleri & 8 \\
\hline Artileri & 3 \\
\hline Arhanud & 2 \\
\hline Penerbad & 3 \\
\hline Zeni & 6 \\
\hline Bekang & 5 \\
\hline Perhubungan & 1 \\
\hline Peralatan & 1 \\
\hline \multicolumn{2}{|l|}{ Sumber } \\
\hline Akademi militer & 60 \\
\hline Sepa PK & 13 \\
\hline \multicolumn{2}{|l|}{ Pendidikan umum } \\
\hline SMA & 8 \\
\hline $\mathrm{S} 1$ & 28 \\
\hline S2 & 37 \\
\hline \multicolumn{2}{|l|}{ Sesko angkatan } \\
\hline Dalam negeri & 65 \\
\hline Luar negeri & 8 \\
\hline
\end{tabular}

Pengumpulan data dilakukan dengan meminta responden mengisi kuesioner online menggunakan Google Form. Adapun karakteristik sampel atau responden yang diambil datanya adalah 73 orang perwira TNI AD yang berdinas di Satuan Seskoad, berpangkat mayor, letnan kolonel dan kolonel, sumber akademi militer maupun perwira karir, dari berbagai macam kecabangan serta pernah mengikuti pendidikan staf dan komando angkatan.

Peneliti melakukan analisis data dengan mengukur reliabilitas instrumen pada masing-masing indikator, di mana item dengan daya beda rendah akan dibuang. Selanjutnya, dilakukan pengujian validitas dengan menggunakan first-order confirmatory factor analysis. Item dengan loading factor 0,4 dikategorikan good (Sharma, 1996) dan t-value harus lebih besar dari 1,96 karena hal tersebut mengindikasikan bahwa faktor-faktor dapat menggambarkan konstrak yang diukur (Simanjuntak et al., 2019). Tahap selanjutnya adalah menguji kembali reliabilitas dan validitas item yang masih bertahan (construct validity) dengan menggunakan second-order confirmatory factor analysis. Pengujian dengan menggunakan second-order confirmatory factor analysis juga dapat mengukur reliabilitas, dalam hal ini validitas konstrak. Jumlah responden dalam penelitian ini berjumlah 73 orang, dengan kriteria prajurit pria dan wanita yang berdinas di Sekolah Staf dan Komando TNI Angkatan Darat.

Tabel 4. Sampel Item

\begin{tabular}{lc}
\hline \multicolumn{1}{c}{ Indikator } & Item \\
\hline How frequently thinks about leaving & Saya sering berfikir untuk pensiun dini. \\
How likely search for a job in another organization & Saya mencari informasi terkait pekerjaan lain di luar \\
& TNI AD yang sepertinya lebih menjanjikan. \\
How likely individual will actually leave within next & Saya memperhitungkan rencana pensiun dini dalam 5 \\
year & tahun ke depan. \\
\hline
\end{tabular}


Alat ukur yang baik haruslah memiliki reliabilitas dan validitas yang baik (Friedenberg, 1995). Alat ukur yang reliabel adalah alat ukur yang memiliki konsistensi dalam mengukur pengetahuan individu yang mengisinya. Penelitian ini menggunakan dan mempertimbangkan reliabilitas internal konsistensi dari alat ukur ITL. Pengukuran reliabilitas dalam penelitian ini menggunakan confirmatory factor analysis (CFA). Reliabilitas konstrak diukur dengan menggunakan loading factors dan pengukuran eror dari setiap item. Alat ukur akan dinyatakan reliabel apabila memiliki koefisien lebih besar dari $0,700(>0,700)$. Pengukuran reliabilitas konstrak dihitung dengan menggunakan formula berikut:

Gambar 1. Construct Reliability Formula

$$
\begin{gathered}
\text { Construct Reliability }=\frac{\left(\sum \text { Standardized Loading }\right)^{2}}{\left(\sum \text { Standardized Loading }\right)^{2}+\sum \varepsilon_{j}} \\
\varepsilon_{j}=1-(\text { Standardized Loading })^{2}
\end{gathered}
$$

$\varepsilon_{j}$ merujuk pada pengukuran eror dari tiap indikator atau observed variable (Fornell \& Larcker, 1981). Nilai batas untuk dapat menentukan bahwa reliabilitas konstrak (construct reliability) dinilai baik adalah lebih besar dari 0,6 (Bagozzi et al., 1992).

Selanjutnya, studi ini juga menganalisis kekuatan diskriminasi item pada setiap item untuk menguji sejauh mana subjek yang berbeda menjawab item dengan cara yang berbeda (Kerlinger, 2006). Daya beda item diperoleh melalui nilai the corrected item-total correlation dari hasil uji reliabilitas.

\begin{tabular}{|c|c|}
\hline Nilai Item Discriminant & Klasifikasi \\
\hline$\geq 0,199$ & Rendah \\
\hline $0,20-0,299$ & Sedang \\
\hline $0,30-0,399$ & Baik \\
\hline$\leq 0,40$ & Sangat Baik \\
\hline
\end{tabular}
Adapun kriteria diskriminan item mengacu pada (Ebel \& Frisbie, 1991) di bawah ini:

Alat ukur yang valid berarti dapat mengukur karakteristik yang relevan dengan konstrak yang akan diukur (Kerlinger, 2006). Penelitian ini menggunakan validasi berdasarkan struktur internal. Uji validitas ini mempertimbangkan bahwa komponen internal dari alat ukur benar-benar sesuai dengan konstrak yang akan diukur. Konfirmasi uji validitas alat ukur ITL dilakukan melalui confirmatory factor analysis (CFA) dengan menggunakan program LISREL 8.80 Full Version dan dianalisis melalui path analysis. Berdasarkan Hu \& Bentler (1999), kriteria untuk menentukan CFA goodness of fit adalah dengan mempertimbangkan root mean square error of approximation (RMSEA), chi-square, goodness of fit index/adjusted goodness of fit index (GFI/AGFI), standardized root mean square residual (SRMR), comparative fit index (CFI), dan normed fit index (NFI).

Nilai RMSEA mengukur deviasi dari nilai parameter pada model dengan populasi matriks kovarians/population covariance matrix (Browne \& Cudeck, 1993 dalam Ghozali, 2005). Selanjutnya, normed fitindex (NFI) yang ditemukan oleh Bentler \& Bonnet (1980) adalah alternatif untuk menentukan kesesuaian dari suatu model (fit model). NFI pun diketahui memiliki tendensi untuk mengabaikan model yang fit pada sampel yang kecil. Bentler (1990) selanjutnya merevisi indeks NFI menjadi comparative fit index (CFI). Nilai NFI dan CFI memiliki rentang antara 0 dan 1 . Suatu model dikatakan fit apabila memiliki nilai NFI dan CFI yang lebih besar atau sama dengan 0,9 (Bentler, 1992 dalam Ghozali, 2005). Non-normed fit index (NNFI) digunakan sebagai solusi dari masalah yang muncul dari kompleksitas model.

Beberapa kriteria lainnya adalah standardized $R M R$ yang merepresentasikan nilai rata-rata dari seluruh standardized residuals dan memiliki rentang nilai antara 0 sampai 1 . Suatu model dikatakan good fit apabila memiliki nilai standardized RMR yang lebih kecil dari 0,05 . Selain itu terdapat goodness of fit indices (GFI) yang digunakan untuk mengukur akurasi dari model dalam menghasilkan observed covariance matrix. Nilai GFI memiliki rentang nilai antara 0 sampai 1 . Nilai GFI yang lebih besar atau sama dengan 0,9 mengindikasikan model yang good fit (Diamantopaulus, 2000 
dalam Ghozali, 2005). Kriteria terakhir yang tidak kalah penting adalah adjusted goodness of fit index (AGFI) yang sama seperti GFI, akan tetapi telah menyesuaikan pengaruh degrees of freedom pada suatu model. Sama seperti GFI, nilai AGFI sebesar 1 menunjukkan bahwa model memiliki kesesuaian yang sangat sempurna, sedangkan model yang fit adalah memiliki nilai AGFI yang lebih besar dari atau sama dengan 0,90 (Diamantopaulus, 2000 dalam Ghozali, 2005).

\section{HASIL DAN PEMBAHASAN}

Secara umum, nilai $t$-value dari tiap item memiliki kontribusi yang signifikan untuk mengukur faktor atau dimensi, yang kemudian akan memiliki kontribusi yang signifikan pula terhadap konstrak intention to leave. Path diagram hasil second-order confirmatory factor analysis dapat dilihat pada Gambar 2 dan Gambar 3.

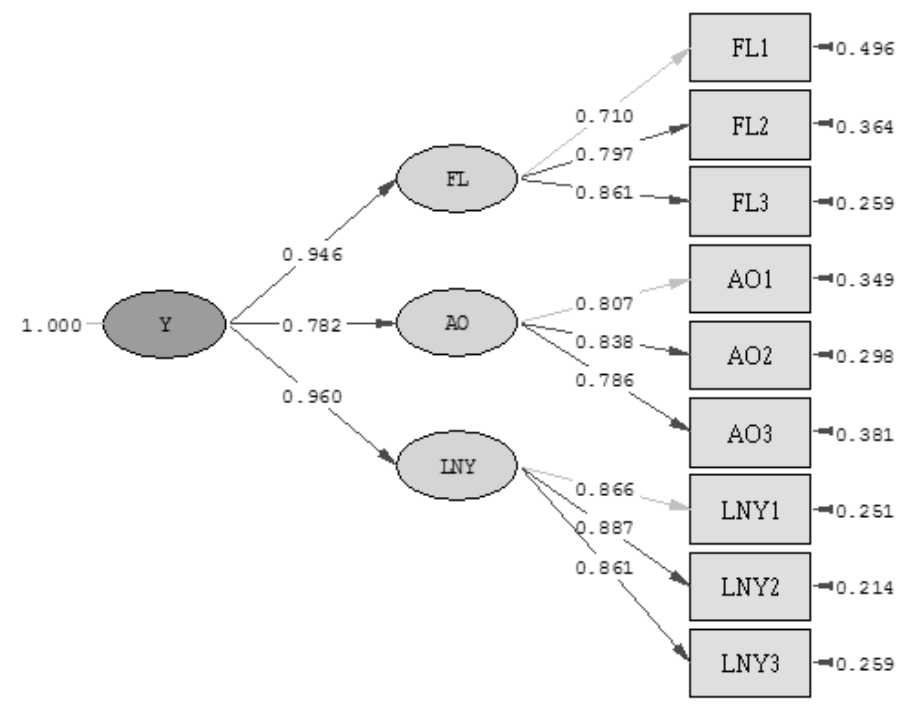

Gambar 2. Loading Factor Second-Order Confirmatory Factor Analysis dari Intention to Leave

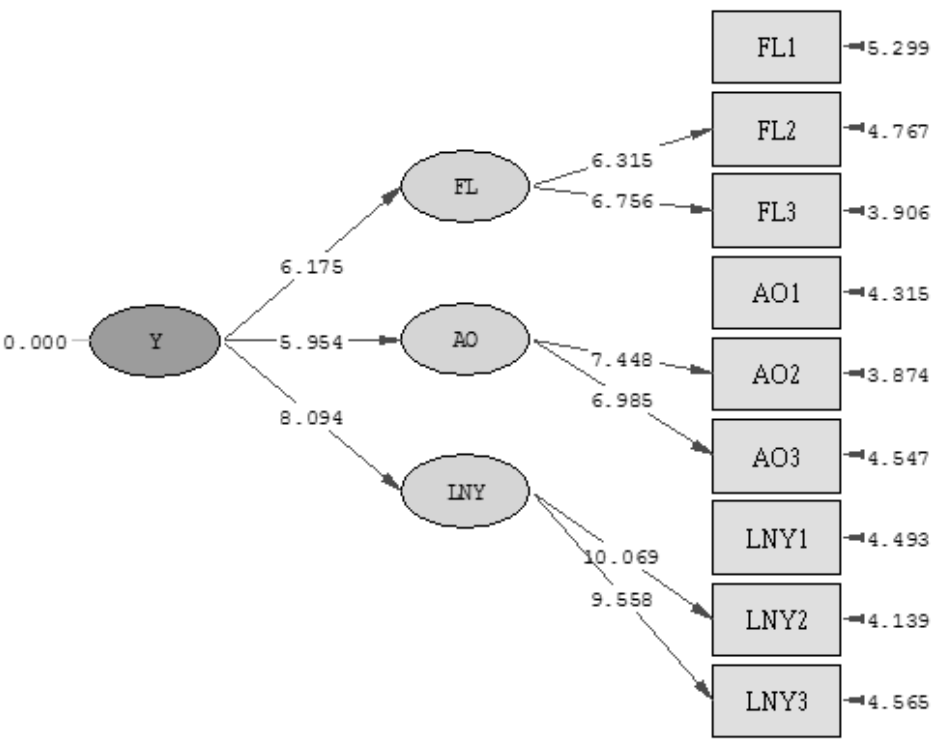

Gambar 3. Nilai t-values Second-Order Confirmatory Factor Analysis dari Intention to Leave 
Gambar 1 menunjukkan nilai loading factor, sedangkan Gambar 2 menunjukkan nilai $t$-value. Y merujuk pada variabel intention to leave dengan FL adalah how frequently thinks about leaving, $\mathrm{AO}$ adalah how likely search for a job in another organization, dan LNY merujuk pada how likely individual will actually leave within next year. Tabel $6 \mathrm{a}$ dan $6 \mathrm{~b}$ juga menunjukkan nilai loading factor dan t-values dari uji second-order confirmatory factor analysis yang memenuhi kriteria. Hasil analisis mengindikasikan bahwa ketiga indikator dari intention to leave adalah valid dan signifikan untuk mengukur variabel intention to leave. Tabel $6 \mathrm{~b}$ menyajikan hasil analisis per faktor dari secondorder confirmatory factor analysis.

Tabel 6a. First-Order Confirmatory Factor Analysis

\begin{tabular}{lcccc}
\hline \multicolumn{1}{c}{ Indikator } & Loading Factor & t-values & $\begin{array}{c}\text { Measurement } \\
\text { Error }\end{array}$ & Keterangan \\
\cline { 1 - 2 } $\begin{array}{l}\text { Saya sering berfikir untuk } \\
\text { pensiun dini }\end{array}$ & & & & \\
$\quad$ FL1 & 0,71 & - & 0,49 & Valid \\
$\quad$ FL2 & 0,79 & 6,31 & 0,36 & Valid \\
$\quad$ FL3 & 0,86 & 6,75 & 0,25 & Valid \\
Saya mencari informasi terkait & & & & \\
pekerjaan lain di luar TNI AD & & & & \\
yang sepertinya lebih & & & & \\
menjanjikan. & 0,80 & - & 0,34 & Valid \\
$\quad$ AO1 & 0,83 & 7,44 & 0,29 & Valid \\
$\quad$ AO2 & 0,78 & 6,98 & 0,38 & Valid \\
$\quad$ AO3 & & & & \\
Saya memperhitungkan & & & & \\
rencana pensiun dini dalam 5 & & -- & 0,25 & Valid \\
tahun ke depan. & 0,86 & 10,06 & 0,21 & Valid \\
$\quad$ LNY1 & 0,88 & 9,55 & 0,25 & Valid \\
$\quad$ LNY2 & 0,78 & & & \\
$\quad$ LNY3 & & & \\
\hline
\end{tabular}

Tabel 6b. Second Order - Confirmatory Factor Analysis

\begin{tabular}{lcccc}
\hline \multicolumn{1}{c}{ Faktor } & Loading Factor & t-values & Deskripsi \\
\cline { 1 - 2 } $\begin{array}{l}\text { Saya sering berfikir untuk pensiun dini } \\
\text { Saya mencari informasi terkait pekerjaan lain di luar }\end{array}$ & 0,94 & 6,17 & & Valid \\
$\begin{array}{llcl}\text { TNI AD yang sepertinya lebih menjanjikan } \\
\begin{array}{l}\text { Saya memperhitungkan rencana pensiun dini dalam } 5 \\
\text { tahun ke depan }\end{array}\end{array}$ & 0,78 & 5,95 & & Valid \\
\hline
\end{tabular}

Nilai $t$-values dan loading factor dari tiap faktor atau dimensi pada hasil second order confirmatory factor analysis menunjukkan bahwa faktor-faktor tersebut dapat mendeskripsikan variabel yang diukur. Hal ini pun menunjukkan bahwa how frequently thinks about leaving, how likely search for a job in another organization, dan how likely individual will actually leave within next year adalah indikator yang menggambarkan intention to leave di TNI AD. Para peneliti di Indonesia dapat menggunakan temuan dalam penelitian ini untuk menginvestigasi fenomena dari intention to leave di TNI AD dengan menggunakan alat ukur yang berhasil dikembangkan pada penelitian ini.

Pada Tabel $6 \mathrm{a}$ dan Tabel $6 \mathrm{~b}$, dapat dilihat bahwa nilai loading factor pada first-order dan seluruh dimensi pada second-order memiliki nilai diatas 0,5 sehingga dapat dikatakan valid.

Tabel 7. Hasil Uji Reliabilitas Konstrak

\begin{tabular}{ccccccc}
\hline $\begin{array}{c}\text { Latent } \\
\text { Variable }\end{array}$ & $\begin{array}{c}\text { Observed } \\
\text { Variable }\end{array}$ & $\begin{array}{c}\text { Standardized } \\
\text { Loading } \\
\text { Factors }\end{array}$ & $\begin{array}{c}\text { Sum of } \\
\text { Standardized } \\
\text { Loading } \\
\text { Factors }\end{array}$ & $\begin{array}{c}\text { Measurement } \\
\text { Errors }\end{array}$ & $\begin{array}{c}\text { Sum of } \\
\text { Measurement } \\
\text { Errors }\end{array}$ & $\begin{array}{c}\text { Construct } \\
\text { Reliability }\end{array}$ \\
\hline \multirow{2}{*}{ FL } & FL1 & 0,710 & & 0,496 & & 0,834 \\
& FL2 & 0,797 & 2,37 & 0,364 & 1,12 & \\
& FL3 & 0,861 & & 0,259 & &
\end{tabular}




\begin{tabular}{lcccccc}
\multirow{4}{*}{ AO } & AO1 & 0,807 & & 0,496 & & \\
& AO2 & 0,838 & 2,43 & 0,364 & 1,12 & 0,841 \\
& AO3 & 0,786 & & 0,259 & & \\
\multirow{2}{*}{ LNY } & LNY1 & 0,866 & & 0,496 & & \\
& LNY2 & 0,887 & 2,61 & 0,364 & 1,12 & 0,859 \\
\hline
\end{tabular}

Berdasarkan Tabel 7 dapat dilihat bahwa seluruh faktor atau dimensi (latent variables) memiliki nilai koefisien construct reliability yang lebih besar dari nilai kriteria $(\mathrm{CR} \geq 0,6)$, sehingga dapat dikatakan bahwa seluruh faktor atau variabel laten adalah reliabel.

Sedangkan pada Tabel 8 dapat dilihat hasil dari goodness of fit second-order confirmatory factor analysis yang diperoleh dari 73 responden penelitian dan 9 item alat ukur ITL.

Tabel 8. Hasil Uji Fit Model Analysis dari Alat Ukur Intention to Leave

\begin{tabular}{cccc}
\hline & Kriteria & Hasil & Keterangan \\
\hline$p$-value & $p$-value not significant & 0,004 & Marginal fit \\
RMSEA & $<0,05$ & 0,113 & Marginal fit \\
Chi-square $/$ df & $<2$ & $46,123 / 24=1,922$ & Good fit \\
NFI & $\geq 0,90$ & 0,945 & Good fit \\
NNFI & $\geq 0,90$ & 0,957 & Good fit \\
CFI & $\geq 0,90$ & 0,971 & Good fit \\
SRMR & $<0,05$ & 0,0501 & Marginal fit \\
GFI & $\geq 0,90$ & 0,875 & Marginal fit \\
AGFI & $\geq 0,90$ & 0,766 & Marginal fit \\
\hline
\end{tabular}

Hasil uji hipotesis menunjukkan bahwa nilai degrees of freedom adalah 24 dan nilai normal theory weighted least squares chi-square adalah 46,123 serta hasil dari p-value sebesar 0,004 . Hal ini menunjukkan bahwa model yang diajukan tergolong dalam klasifikasi marginal fit karena nilai $p$-value yang dihasilkan masih lebih besar dari batas nilai minimal yang direkomendasikan, yaitu 0,05 . Hasil menunjukkan nilai RMSEA $>0,05$, yaitu 0,113 , sehingga dapat dikatakan bahwa model memiliki kriteria marginal fit.

Selanjutnya, diketahui bahwa model yang diajukan dalam penelitian ini memiliki nilai NFI sebesar 0,945 dan nilai CFI 0,971. Apabila nilai NFI dan CFI lebih besar dari nilai batas 0,90, maka model yang diajukan dianggap fit. Hasil analisis menunjukkan bahwa nilai NFI dan CFI yang diperoleh lebih besar dari 0,90, sehingga dapat disimpulkan bahwa model yang diajukan fit. Model yang diajukan pada penelitian ini memiliki nilai RMR sebesar 0,0501. Karena nilai RMR lebih besar dari 0,05 , model yang diajukan pun tergolong dalam marginal fit. Kemudian, model yang diajukan pada penelitian ini diketahui memiliki nilai GFI sebesar 0,875. Karena nilai GFI lebih kecil dari 0,90, maka dapat disimpulkan bahwa model yang diajukan tergolong dalam marginal fit. Kriteria akhir dari penelitian menemukan model yang diajukan dalam penelitian ini memiliki nilai AGFI sebesar 0,766. Nilai AGFI yang diperoleh lebih kecil dari batas cut-off yang disarankan, sehingga model pun dinilai sebagai marginal fit.

Pada penelitian sebelumnya yang melakukan pengukuran intention to leave terhadap 366 siswa keperawatan dan 603 perawat, diketahui bahwa alat ukur yang diuji memiliki nilai validitas dan reliabilitas yang baik (Meyer et al., 1993). Selain itu, Stallworth (2003) juga melakukan pengukuran kepada 107 akuntan publik yang berada di bawah naungan American Institute of Certified Public Accountant dengan hasil validitas dan reliabilitas yang baik pula. Kedua penelitian tersebut menggunakan konstrak yang sama dengan penelitian ini, dan diketahui bahwa tidak terdapat perbedaan hasil dengan keduanya. Hal ini menunjukkan bahwa alat ukur dalam penelitian ini dapat digunakan di lingkungan TNI AD untuk mengukur keinginan pensiun dini pada para perwira.

Menurut Hu \& Bentler (1999) jumlah sampel minimal dalam kriteria penelitian yaitu antara 60 hingga 120, sehingga kriteria sampel dalam penelitian ini telah memenuhi syarat minimum. Namun demikian peneliti menyarankan agar penelitian selanjutnya dapat melibatkan sampel penelitian yang lebih besar, yaitu minimal antara 200 (Singh et al., 2016). Jika memungkinkan penelitian dapat 
dilakukan dengan melibatkan sampel sampai 300 responden (Tabachnick \& Fidell, 2012). Peningkatan jumlah sampel bertujuan untuk meningkatkan pembuktian validitas alat ukur ITL. Selanjutnya, peneliti juga menyaranksan agar penelitian berikutnya dapat mempertimbangkan dan mengikutsertakan variabel lain, seperti latar belakang demografi, serta dapat diberikan pada Golongan Bintara atau Golongan Tamtama ke dalam model pengukuran agar dapat memperoleh hasil pengukuran yang lebih luas dalam menggambarkan ITL prajurit di TNI AD.

\section{SIMPULAN}

Berdasarkan tahapan pengembangan alat ukur yang telah dilakukan, studi ini telah berhasil menyusun suatu alat ukur intention to leave dengan item-item dari dimensi berpikir untuk pensiun dini, mencari pekerjaan lain di luar TNI AD, dan memperhitungkan rencana pensiun dini dalam 5 tahun ke depan, serta reliabel untuk mengukur keinginan perwira yang ingin keluar dari organisasi TNI AD. Secara teoritis, peneliti intention to leave di Indonesia, khususnya di lingkungan TNI AD, diharapkan dapat mempertimbangkan karakteristik sampel yang lebih luas dari berbagai korps serta mempertimbangkan karakteristik satuan lain dengan bermacam tuntutan tugas berbeda yang ada di TNI $\mathrm{AD}$, sehingga dapat diperoleh gambaran validitas dan reliabilitas secara lebih luas. Selanjutnya, alat ukur ini juga diharapkan dapat diujicobakan kepada Golongan Bintara dan Golongan Tamtama untuk mengetahui apakah alat ukur ini dapat digeneralisasikan ke berbagai golongan prajurit di TNI AD. Dalam tataran aplikatif, dengan mengetahui keinginan prajuritnya untuk berhenti dari kedinasan lebih awal, TNI AD dapat melakukan tindakan pencegahan sebagai upaya preventif dalam mempertahankan retensi. Apabila hasil pengukuran semakin mendekati akurasi realitas pada kondisi nyata di lapangan, hasil pengukuran pun dapat dijadikan asesmen yang selanjutnya dapat ditindaklanjuti dalam bentuk intervensi.

\section{DAFTAR PUSTAKA}

Bagozzi, R. P., Baumgartner, H., \& Yi, Y. (1992). State versus action orientation and The Theory Of Reasoned Action: An application to coupon usage. Journal of Consumer Research, 18(4), 505.

Bowen, G. L. (1986). Spouse support and the retention intentions of air force members. A basis for program development. Evaluation and Program Planning, 9(3), 209-220.

Chen, G., Ployhart, R. E., Thomas, H. C., Anderson, N., \& Bliese, P. D. (2011). The power of momentum: A new model of dynamic relationships between job satisfaction change and turnover intentions. Academy of Management Journal, 54(1), 159-181.

Daula, T., \& Moffitt, R. (1995). Estimating dynamic models of quit behavior: The case of military reenlistment. Journal of Labor Economics, 13(3), 499-523.

Ebel, R. L., \& Frisbie, D. A. (1991). Essentials of educational measurement. Journal of School Psychology, 11(2), 172-173.

Firth, L., Mellor, D. J., Moore, K. A., \& Loquet, C. (2004). How can managers reduce employee intention to quit. Journal of Managerial Psychology, 19(2), 170-187.

Fornell, C., \& Larcker, D. F. (1981). SEM with unobservable variables and measurement error: Algebra and statistics. Journal of Marketing Research, 18(3), 1-16.

Friedenberg, L. (1995). Psychological testing: Design, analysis and use. MA: Allyn \& Bacon.

GAO. (1999). Military personnel: Perspectives of surveyed service members in retention critical specialties: Briefing report to congressional requesters.

GAO. (2000). Army national guard: Enhanced brigade readiness improved but personnel and workload are problems.

Ghozali, I. (2005). Structural Equation Modelling: Teori, konsep, \& aplikasi dengan program LISREL 8.54. Badan Penerbit Universitas Diponegoro.

Griffeth, R. (2000). A meta-analysis of antecedents and correlates of employee turnover: update, moderator tests, and research implications for the next millennium. Journal of Management, 26(3), 463-488.

Hair, J. F., Black, W. J., Babin, B. J., \& Anderson, R. E. (2010). Multivariate data analysis. Englewood Cliff, NJ: Prentice Hall. 
Hosek, J. R., \& Peterson, C. E. (1985). Reenlistment Bonuses and retention behavior. The Rand Corporation.

Hu, L. T., \& Bentler, P. M. (1999). Cutoff criteria for fit indexes in covariance structure analysis: Conventional criteria versus new alternatives. Structural Equation Modeling, 6(1), 1-55.

Kerlinger, F. N. (2006). Asas-asas penelitian behavioral. Gadjah Mada University Press.

Kocher, K. M., \& Thomas, G. W. (1994). Retaining army nurses: A longitudinal model. Research in Nursing \& Health, 17(1), 59-65.

Latan, H. (2012). Structural equation modeling: Konsep dan aplikasi menggunakan program LISREL 8.80. Bandung: Alfabeta.

Maertz, C. P., \& Campion, M. A. (2004). Profiles in quitting: Integrating process and content turnover theory. Academy of Management Journal, 47(4), 566-582.

Mafini, C., \& Dubihlela, J. (2013). Determinants of military turnover of technical air-force specialists: An empirical case analysis. Mediterranean Journal of Social Sciences, 4(3), 523-534.

Marcotte, D. E. (2000). Continuing education, job training, and the growth of earnings inequality. Industrial and Labor Relations Review, 53(4), 602-623.

Meyer, J. P., Allen, N. J., \& Smith, C. A. (1993). Commitment to organizations and occupations: extension and test of a three-component conceptualization. Journal of Applied Psychology, 78(4), 538-551.

Mueller, C. W., \& Price, J. L. (1990). Economic, psychological, and sociological determinants of voluntary turnover. Journal of Behavioral Economics, 19(3), 321-335.

Price, J. L., \& Mobley, W. H. (1983). Employee turnover: causes, consequences, and control. Industrial and Labor Relations Review, 36(3), 506.

Schreurs, B., \& Lescreve, F. (2001). Voluntary turnover in the Belgian Army: Unmet expectations and the role of information provision. 1-9.

Sharma, S. (1996). Applied multivariate techniques.

Simanjuntak, E., Fajrianthi, F., Purwono, U., \& Ardi, R. (2019). Skala cyberslacking pada mahasiswa. Jurnal Psikologi, 18(1), 55-68.

Singh, K., Junnarkar, M., \& Kaur, J. (2016). Measures of positive psychology: Development and validation. Springer.

Spreitzer, G. M., \& Mishra, A. K. (2002). To stay or to go: Voluntary survivor turnover following an organizational downsizing. Journal of Organizational Behavior, 23(6), 707-729.

Stallworth, H. L. (2003). Mentoring, organizational commitment and intentions to leave public accounting. Managerial Auditing Journal, 18(5), 405-418.

Stone, B., Wiggins, V., Turner-Holland, T., \& Looper, L. T. (1998). Air force pilot retention: Evaluating the results of alternative models. Armed Forces \& Society, 25(1), 90-192.

Sümer, H. C., \& Van De Ven, C. (2007). A proposed model of military turnover. In Recruiting and retention of military personnel.

Tabachnick, B. G., \& Fidell, L. S. (2012). Using multivariate statistics (6th ed.).

United Kingdom Ministry of Defence. (2020). UK Armed Forces quarterly service personnel statistics 1 July 2020.

Van Schalkwyk, S., Du Toit, D. H., Bothma, A. S., \& Rothmann, S. (2010). Job insecurity, leadership empowerment behaviour, employee engagement and intention to leave in a petrochemical laboratory. SA Journal of Human Resource Management, 8(1). 